\title{
REVISIÓN DEL TRATAMIENTO DE LAS NORMAS ORTOGRÁFICAS DE LAS GRAFÍAS $G$ Y J EN MANUALES DE SEGUNDO Y TERCER CICLO DE EDUCACIÓN PRIMARIA Y SUS REPERCUSIONES EN LA ENSEÑANZA
}

\author{
Serafín Ayala Ato \\ Andrés Montaner Bueno \\ Universidad de Murcia
}

\begin{abstract}
RESUMEN: El objetivo de este estudio consiste en analizar el nivel de competencia ortográfica respecto al empleo de las grafías $g$ y $j$ que posee el alumnado de sexto curso de Educación Primaria. Para ello, nos servimos de una muestra constituida por 120 alumnos a la que aplicamos un cuestionario de naturaleza teórico-práctica para determinar el dominio que estos poseen sobre las normas de uso que regulan estos contenidos. Los resultados del mismo nos muestran que el grado de adquisición de estas reglas es bastante deficiente, pues solo 24 estudiantes cuentan con algún sucinto conocimiento sobre las disposiciones teóricas y únicamente 7 son capaces de realizar de forma satisfactoria las actividades propuestas.

Una de las causas de estos malos resultados creemos que se encuentra en la perspectiva didáctica con la que los libros de texto abordan la explicación de estos preceptos. A este respecto, hemos realizado una indagación crítica sobre la forma en que los manuales más utilizados en esta etapa educativa tratan los contenidos ortográficos acerca de la $g$ y la $j$ que vienen exigidos por los currículos escolares actualmente vigentes (LOE y LOMCE).
\end{abstract}

PALABRAS CLAVE: Didáctica, Educación Primaria, normas de ortografía, desarrollo del curriculum.

\section{REVIEW OF THE TREATMENT OF THE ORTHOGRAPHIC RULES OF THE SPELLING $G$ AND $J$ IN THE MANUALS OF SECOND AND THIRD CYCLE OF PRIMARY EDUCATION AND ITS IMPACT ON TEACHING}

\footnotetext{
ABSTRACT: The objective of this study is to analyze the level of spelling competence regarding the use of the spelling $g$ and $j$ which the students of sixth year of primary education have. To do this, we use a sample composed of 120 students to which we apply a questionnaire of theoretical and practical nature
} 
to determine the domain that they have about the rules of use that regulate these contents. The results of this show us that the degree of acquisition of these rules is quite poor, as only 24 students have some concise knowledge of theoretical provisions and only 7 are able to perform the proposed activities successfully.

We believe that one of the causes of these poor results is in the didactic perspective with which textbooks deal with the explanation of these precepts. In this respect, we have made a critical research in the way in which the most used textbooks in this educational stage deal with the spelling content about $\mathrm{g}$ and $\mathrm{j}$ and which are also required by the existing school curricula (LOE and LOMCE).

KEYWORDS: Didacticism, Primary Education, spelling instruction, curriculum development.

Recibido: 11/12/2015

Aceptado: 27/09/2016

Correspondencia: Andrés Montaner Bueno, Universidad de Murcia, Didáctica de la Lengua y Literatura, Campus de la Merced, 30071 Murcia. Email: andres.montaner@um.es.

\section{INTRODUCCIÓN}

La ortografía, hoy en día, parece encontrarse en una gran encrucijada. Nos hallamos en una era donde, cada vez más, impera lo digital y, producto de ello, la despreocupación por esta parte de la gramática. Es fácil apreciar numerosos errores ortográficos en redes sociales o chats, fruto del uso, cada vez mayor, de los dispositivos multimedia.

A menudo, estos errores suelen achacarse a lo reducido del espacio para teclear o a la proximidad entre las diferentes grafías (por ejemplo la $b$ y la $v$ en los teclados), además de la rapidez con la que se utilizan, primando esta sobre la precisión ortográfica. Sin embargo, el problema es más grave y, quizá, podría tratarse de que muy pocas personas llegan a adquirir, durante la escolaridad obligatoria, las nociones ortográficas necesarias para realizar un escrito correcto.

Con este estudio pretendemos analizar con qué conocimientos sobre las normas ortográficas referidas al uso de las grafías $g$ y $j$ abandonan los estudiantes la etapa educativa de la Educación Primaria, la cual es clave para establecer las bases de los futuros aprendizajes.

Para ello, abordamos, en los distintos apartados, todo lo concerniente a la enseñanza de las normas ortográficas que rigen el uso de las grafías indicadas anteriormente. Así, en primer lugar, analizamos la importancia que tiene la ortografía dentro de la etapa educativa de la Educación Primaria. Después, indicamos las normas ortográficas que, según la Ortografía de la lengua española (2010), marcan el uso de estas grafías y cómo se recogen estas en los currículos de esta etapa educativa, así como en los libros de texto utilizados en algunos de los colegios de la Región de Murcia. 
Finalmente, mostramos el estudio llevado a cabo y algunas propuestas de mejora para trabajar las normas ortográficas de manera diferente, apostando por un papel más activo de los alumnos.

\section{Importancia de la ortografía en Educación Primaria}

Si nos atenemos a los currículos oficiales que han regulado, y regulan, la Educación Primaria en los últimos años vemos, de manera general, que en ellos se hace referencia al desarrollo integral del alumno, de forma que el paso de este por las diferentes etapas educativas sea lo más satisfactorio posible, y culmine con la formación de ciudadanos activos y participativos en la sociedad en la que se insertan. Así, el Decreto 286/2007 (p. 26387) recoge que esta etapa "es especialmente importante ya que se inicia la escolarización obligatoria y se ponen las bases de todo el aprendizaje posterior". Del mismo modo, en el Decreto 198/2014 (p. 33055), el cual complementa al anterior, se indica que esta etapa "es determinante por cuanto se construyen en ella las bases del pleno desarrollo de la personalidad, así como el conjunto de conocimientos, recursos y herramientas de aprendizaje que capacitan a los alumnos para cumplir con éxito sus objetivos".

Dentro de esta formación integral del alumno, creemos que supone un pilar importante el desarrollo de las habilidades comunicativas, entre las que se encuentra la escritura. En los citados decretos se hace referencia también a este hecho. Por ejemplo, en el Decreto 287/2007 (p. 26387) se hace hincapié en "la transcendencia de alentar el interés por la lectura, el dominio de la escritura y, en general, de los lenguajes esenciales (...)". A pesar de ello, somos conscientes de que el desarrollo de esta habilidad es una tarea ardua para numerosos discentes, no solo de la etapa educativa que nos ocupa, sobre todo, por la cantidad de procesos cognitivos implicados en ella ya que:

Es un proceso complejo y exigente, dado que el escritor debe tener en cuenta varios factores como la organización, forma, características, propósitos y metas, perspectivas y necesidades del auditorio, la evaluación de la comunicación entre el autor y el lector, y los procesos de autorregulación que llevan al escritor a tener una meta orientada, reflexiva y recursiva. (González, 2002, p. 15)

Asimismo, coincidimos con Cassany (2003, p. 64) cuando indica que "la cantidad de convenciones que requiere el acto de escritura es muy elevada". Todas estas convenciones son las que nos marca la ortografía, disciplina en la Ortografía de la lengua española (2010, p. 10) como el "conjunto de normas que determinan el valor y correcto uso de los constituyentes del sistema de escritura de una lengua". Por tanto, hemos de ser conscientes de que, como indica Avendaño (2007, p. 4), "reflexionar acerca de la ortografía remite a un fenómeno complejo en el que interjuegan los aspectos representativos y los convencionales".

Por todo ello, creemos que conocer y dominar la ortografía es imprescindible si lo que se busca es asegurar la correcta comunicación escrita entre los hablantes de una misma lengua, ya que garantiza, no solo la adecuada creación de textos, sino también la correcta interpretación de estos. Este aspecto es el que marca la importancia de la ortografía, al considerarla como condición necesaria para el desarrollo 
completo de la persona, tanto individualmente como en su inserción en la sociedad, ya que la escritura es fundamental como soporte del conocimiento y como instrumento de comunicación. Por lo tanto, la ortografía debería ocupar un lugar esencial en el sistema educativo, cuya base debe ser la Educación Primaria, debido a que su aprendizaje es indisociable de otros como la lectura y la escritura, las cuales son indispensables en la formación de todo ciudadano (Ortografía de la lengua española, 2010). A pesar de ello, tal y como indican estudios como el de Sotomayor, Molina, Bedwell y Hernández (2013), somos conscientes de que los alumnos van adquiriendo el sistema ortográfico a medida que avanzan en los niveles o etapas educativas.

En lo que respecta a la enseñanza de la ortografía, son varios los enfoques que los docentes pueden utilizar para la transmisión de los conocimientos ortográficos y la correcta aprehensión de estos por parte de los discentes. De acuerdo con Navarro (2015), señalamos como principales los siguientes: tradicional, socio-constructivista, comunicativo o funcional y PNL (Programación Neurolingüística).

No obstante, como indica Camps (1993, p. 10), "hemos de tener presente que el valor dado a la ortografía varía según las épocas, las diferentes técnicas pedagógicas o, incluso, el criterio de las escuelas". Sin embargo, no podemos negar su importancia o presencia ya que, en mayor o menor medida, siempre ha formado parte de los contenidos impartidos en las diferentes etapas educativas.

A pesar de ello, somos conscientes de que, por un lado, como indica Zayas (2007), la ortografía, desde un punto de vista lingüístico, es uno más de los componentes del lenguaje escrito, no es ni el único ni el más importante. Por otro lado, pensamos que, como indica un reciente estudio de Navarro (2015), los docentes juegan un papel básico en la enseñanza de la ortografía y, a pesar de ser conscientes de las carencias de los discentes en el plano ortográfico, tal vez, el enfoque didáctico utilizado para la enseñanza de la ortografía no sea el más adecuado, sobre todo, si este se basa en la enseñanza de tareas rutinarias, que no siguen un enfoque comunicativo, como pueden ser los dictados y la explicación teórica de las normas de ortografía, las cuales se trabajan, de manera práctica, a través de ejercicios, de corte muy similar, propuestos en los libros de texto. Y es que, como indican Díaz y Manjón (2010), en la didáctica de la composición escrita, en la mayoría de las veces, después de la explicación, la intervención docente se basa en corregir el producto terminado, haciendo especial hincapié en los aspectos ortográficos.

Finalmente, hemos de destacar la importancia social de la ortografía. Como se indica en la Ortografía de la lengua española (2010), es la propia sociedad la que recompensa a quienes dominan esta disciplina con una buena imagen social y profesional. Asimismo, es también la sociedad la que estima como faltas los errores ortográficos y sanciona a las personas que muestran una ortografía deficiente. En el ámbito educativo ocurre lo mismo, teniendo una mejor calificación, imagen y promoción académica aquellos alumnos que dominan la competencia ortográfica en relación con los que no la tienen. Por todo ello, creemos que desde la etapa educativa de la Educación Primaria se deben sentar las bases, mediante los enfoques didácticos adecuados, para que los alumnos dominen la ortografía y puedan hacer un uso pleno de la competencia comunicativa, contribuyendo así, de manera significativa, a desarrollar un pilar fundamental en la formación integral de los alumnos. 


\section{Normas ortográficas y curriculum de Educación Primaria}

En este apartado, primeramente, abordaremos las normas ortográficas que rigen el uso de las grafías $g$ y $j$ y, posteriormente, detallaremos cómo recoge el Decreto 286/2007 las normas ortográficas que son objeto de nuestro estudio. Del mismo modo, analizaremos los planteamientos que establece el nuevo Decreto 198/2014 en lo referido a las normas ortográficas que guían este trabajo.

\section{Normas ortográficas g y j}

La Real Academia Española, en adelante RAE, indica en la Ortografía de la lengua española (2010), entre otros muchos aspectos, las normas que rigen la correcta escritura de las grafías $g$ y $j$.

El fonema /g/ puede aparecer con la grafía g o con el dígrafo gu dependiendo de la posición que dicho fonema ocupe dentro de la palabra y, sobre todo, de cuál sea el fonema siguiente. Así, la grafía $g$ aparece ante las vocales /a/, /o/, /u/ y al final de la palabra en términos prestados de otras lenguas. El dígrafo gu se emplea ante las vocales /e/, /i/.

El fonema / $\mathrm{x} /$ puede aparecer con las grafías g y j y, ocasionalmente con la grafía $x$. La letra $j$ puede representar dicho fonema en cualquier posición y ante cualquiera de las vocales. La grafía $g$, en cambio, solo puede representar el fonema /x/ delante de las vocales /e/, /i/.

La RAE (2010), ofrece las notas orientadoras sobre el uso de la grafía $j$ ante $e, i$. Esta puede utilizarse, según criterios posicionales o secuenciales, en los siguientes casos:

- En las palabras que empiezan por eje-, con algunas excepciones como egetano y Egeo.

- En las palabras que terminan en -aje y en -eje, con las excepciones: enálage, hipálage...

- En las palabras de acentuación Ilana que acaban en -jero/a, con la excepción de ligero.

- En los verbos terminados en -jear, con la excepción de aspergear.

- En los sustantivos que acaban en -jeria.

Según criterios morfológicos y léxicos, en los siguientes casos:

- En todas las formas verbales que contienen dicho fonema careciendo en su infinitivo de él. Afecta a verbos cono decir y traer y a los verbos acabados en -ducir en diversas formas verbales.

De igual modo, también muestra las notas orientadoras sobre el uso de la grafía $g$ ante $e, i$.

Según criterios posicionales o secuenciales, se puede utilizar en los casos siguientes:

- En palabras que contienen la secuencia inge en cualquier posición, con las excepciones de injerir, injerencia e injerto.

- En palabras que contienen la sílaba gen en cualquier posición, incluidas las acabadas en -gencia o -gente, con las excepciones de ajenjo, jengibre, ojén, avejentar y las formas verbales de los verbos acabados en -jar, -jer, -jir. 
- En las palabras que contienen la secuencia -gest- con las excepciones de majestad y vejestorio.

- En las palabras que contienen las secuencias gia, gio lleven o no acento, con algunas excepciones.

- Las palabras que empiezan por gene-, geni-, geno-, genu-.

- Las palabras que empiezan por legi-, con la excepción de lejía.

- Las palabras acabadas en -gésimo/a y -gesimal.

- Las palabras terminadas en -ginoso/a.

- Los verbos terminados en -ger, -gir, exceptuando los verbos tejer y crujir.

Según los criterios morfológicos se escribe $g$ ante $e, i$ en las siguientes raíces léxicas grecolatinas: angio-, geo-, -geo, german(o)-, -german(o), ger(onto)-, giga-, gine(co)-; y en las palabras que terminan por las siguientes raíces léxicas grecolatinas: -algia, -fagia, -génesis, -genia, -génito, -geno/a, -gero/a, -logía, -rragia.

\section{Decreto 286/2007'}

Esta ley, complementada por la actual, se caracteriza por la división de los cursos educativos en tres ciclos de dos años cada uno. Para cada asignatura, en cada ciclo, plantea unos contenidos, criterios de evaluación y contribución de estos al cumplimiento de las competencias básicas. Asimismo, establece, de manera general, unos objetivos de etapa, así como unos objetivos específicos que se deben cumplir en cada área de aprendizaje.

El primer análisis en esta ley educativa, lo llevaremos a cabo con los objetivos: diferenciando entre los de etapa y los de área.

Así, en el artículo 4. Objetivos de la etapa, el único que encontramos que pueda hacer referencia al dominio de la competencia ortográfica es el siguiente (p. 26389):

Conocer y utilizar de manera apropiada la lengua castellana, valorando sus posibilidades comunicativas desde su condición de lengua común de todos los españoles y de idioma internacional, y desarrollar hábitos de lectura como instrumento esencial para el aprendizaje del resto de las áreas.

En lo que respecta a los objetivos del área, creemos que, solo, dos de los objetivos que se plantean tienen relación con la adquisición de una correcta competencia ortográfica. Tenemos por un lado, (p. 26417) "Expresarse oralmente y por escrito de forma adecuada en los diversos contextos de la actividad social y cultural para satisfacer necesidades de comunicación, así como explorar cauces que desarrollen la sensibilidad, la creatividad y la estética". Y por otro lado, (p. 26418):

Usar los conocimientos sobre la lengua y las normas del uso lingüístico para escribir y hablar de forma adecuada, coherente y correcta, cuidando la estructura del texto, los aspectos normativos, la caligrafía, el orden y la limpieza, y para comprender textos orales y escritos.

1. Decreto número $287 / 2007$, de 7 de septiembre, por el que se establece el currículo de la Educación Primaria en la Comunidad Autónoma de la Región de Murcia. 
En lo referido a los contenidos de aprendizaje, solo encontramos referencia directa a las normas ortográficas, estudiadas en este documento en el segundo ciclo, en dos bloques de contenidos. Por un lado, en el bloque 2. Leer y escribir (p. 26424), en el contenido:

Valoración y uso de las normas ortográficas (conocer y usar las correspondencias regulares entre sonido y letra: ro rr entre vocales, ce-ze, ci-zi, ge-je, gi-ji, que, qui); las que regulan la acentuación gráfica, los signos de puntuación y la acentuación de palabras frecuentes, mediante, entre otras técnicas, el dictado, para escribir correctamente, desde el punto de vista ortográfico, palabras de uso habitual.

Por otro lado, en el bloque 4. Conocimiento de la lengua (p. 26428), en el contenido:

Conocimiento de las normas básicas de la ortografía apreciando su valor social y la utilización constante en los propios escritos. Aplicación de las reglas ortográficas básicas en las palabras de uso frecuente. Uso de los principales signos de puntuación. Preocupación por consultar dudas y palabras de ortografía difícil.

No obstante, en el tercer ciclo también aparecen, en el bloque 4, dos contenidos que abarcan la competencia ortográfica, aunque de manera más alejada, siendo estos "Sistematización de la ortografía, apreciando su valor social y la utilización constante en los propios escritos. Uso de los signos de puntuación para cohesionar el texto y superar el lenguaje enumerativo" y "Explicitación de conocimientos gramaticales que se dominan implícitamente. Consolidación de nociones gramaticales, léxicas, fonológicas y ortográficas adquiridas en ciclos anteriores. Descubrimiento y nuevas incorporaciones. Aplicación de estos conocimientos a la propia producción discursiva".

En lo concerniente a los criterios de evaluación, el único que guarda relación con la ortografía es el número 6, el cual es el mismo para los tres ciclos, con la lógica graduación de la dificultad a medida que se avanza en los ciclos.

\section{Decreto $198 / 2014^{2}$}

Este nuevo Decreto es bien distinto en su forma de proceder, sobre todo, si lo comparamos con su antecesor. La primera diferencia la encontramos en la eliminación de los ciclos, ya que este Decreto plantea dos tramos educativos.

En lo que respecta al planteamiento del currículo, este es diferente a la LOE debido a que aparecen los contenidos que deben abordarse, en las diferentes asignaturas, en cada curso. Igualmente, complementa cada contenido con los criterios de evaluación que le corresponden, así como los estándares de aprendizaje evaluables.

Dicho Decreto no contiene los objetivos de etapa que se deben perseguir durante la Educación Primaria. Estos objetivos aparecen en el Real Decreto 126/2014 en su artículo 7. De estos objetivos, el único relacionado con la adquisición y dominio de

2. Decreto número 198/2014, de 5 de septiembre, por el que se establece el currículo de la Educación Primaria en la Comunidad Autónoma de la Región de Murcia.

3. Real Decreto 126/2014, de 28 de febrero, por el que se establece el currículo básico de la Educación Primaria. 
la lengua, y por ende, de la ortografía, es el siguiente: "Conocer y utilizar de manera apropiada la lengua castellana y, si la hubiere, la lengua cooficial de la Comunidad Autónoma y desarrollar hábitos de lectura" (p. 19354).

En cuanto a las normas o reglas ortográficas que determina en los contenidos, estas son más sintéticas y directas que las dispuestas en el Decreto 287/2007, predominando en los bloques 3 y 4 y estando más referidas a las normas de los signos de puntuación y al uso de las mayúsculas. Así, podemos indicar que en dicho Decreto no se hace alusión, en ningún contenido, a las reglas o normas ortográficas referidas a las grafías $g$ y $j$.

\section{Tratamiento de la $\mathrm{g} / \mathrm{j}$ en los libros de texto}

En este apartado abordaremos el análisis de los libros de texto utilizados, en los ciclos segundo y tercero, por parte de los colegios en los que se pasó el cuestionario. Solo se han analizado los manuales de los dos últimos ciclos ya que es en ellos cuando, desde las leyes educativas, se empiezan a introducir los conocimientos de las normas ortográficas. En lo que a editoriales respecta, la mayoría de los alumnos han utilizado el manual de la editorial Santillana (Proyecto La Casa del Saber), no obstante, en uno de los centros, la editorial utilizada en cuarto curso y el tercer ciclo era la editorial SM (Proyecto Tirolina en cuarto y Timonel en tercer ciclo).

\section{Revisión del manual de la editorial Santillana (Proyecto La Casa del Saber)}

De este manual revisaremos los libros pertenecientes a los ciclos segundo y tercero, es decir, los cursos tercero, cuarto, quinto y sexto. Los contenidos de la lengua, en el citado manual, se estructuran de manera distinta dependiendo del ciclo educativo. Así, en el segundo ciclo, cursos tercero y cuarto, los contenidos se dividen en siete bloques, siendo estos: lectura, vocabulario, gramática, ortografía, escritura, comunicación oral y, finalmente, talleres. En el tercer ciclo, cursos quinto y sexto, se añaden, a los siete contenidos que ya aparecían, dos nuevos: escritura y texto para trabajar las competencias básicas. Una vez descrito el índice que establece la editorial, pasamos a analizar el tratamiento que hace de las grafías que son objeto de nuestro estudio.

En nuestro caso, examinaremos el tratamiento que, dicha editorial, hace de los sonidos $[\mathrm{g}]$ y $[\mathrm{x}]^{4}$, así como el uso de las palabras que contienen $g \mathrm{y} j$. Estos aspectos se encuentran dentro del apartado de ortografía que plantea el citado manual. Del mismo modo, al final de cada trimestre incluye ejercicios de repaso en los que se tratan los temas abordados.

En los libros de tercero y cuarto, aparecen las cuestiones que se estudian de manera separada. En el libro de tercero encontramos el sonido [g], en el tema 3 (p. 50), en un apartado denominado el sonido G suave; mientras que el sonido [x] lo encontramos en el tema 7 (p. 92). En cuanto a las explicaciones y ejercicios que plantea, no sigue una línea de explicación y aplicación de lo aprendido ni se realiza un enfoque constructivo-comunicativo, sino que se basa en un enfoque reglado transmisivo (Díaz y Manjón 2004; en Díaz 2008). En el caso del sonido [g]

4. Según el A.F.I. Alfabeto Fonético Internacional. 
integra los sonidos ga, gue, gui, go, gu y gü a partir de una breve lectura y con una breve explicación que incluye el primer ejercicio, indicando en cada caso cómo se escribe este sonido. Los ejercicios que plantea son de aplicación fonológica, buscando establecer una correcta ortografía natural del lenguaje, haciendo que los alumnos relacionen el sonido con la grafía correcta y culminando con un dictado. En lo que respecta al sonido [x], el procedimiento es, básicamente, el mismo. En este caso, la explicación que realiza del sonido [x] puede llevar a confusión ya que indica que este sonido se escribe con las grafías $j$ o $g$, dependiendo de si lleva delante las vocales $e, i$, pero no aclara en qué casos se ha de utilizar cada una.

En el libro de cuarto, encontramos tres divisiones: por un lado, tenemos Verbos terminados en -ger, -gir, tema 6 (p. 78); por otro lado, la $j$ en los verbos, tema 12 (p. 158); $y$, finalmente, palabras con $j$, en el tema 14 (p. 184). En cada uno de estos apartados se sigue el mismo criterio expuesto anteriormente: primero lectura con algunas palabras que ejemplifican la norma que se quiere abordar, breve explicación de la norma ortográfica y una serie de ejercicios de aplicación de la norma, en la mayor parte de los casos de completar la palabra con la letra que falta, y, finalmente, un dictado. Las normas ortográficas de la g/j que se tratan en este manual son las siguientes:

- El tema 6 aborda la norma: se escriben con g todos los verbos acabados en -ger $o$-gir, excepto tejer y crujir.

- El tema 12 recoge la norma: se escriben con j las formas de los verbos que llevan el sonido $[\mathrm{x}]$ y no tienen ni $g$ ni $j$ en el infinitivo.

- El tema 14 trata la norma: se escriben con $j$ las palabras que terminan en -aje y en -eje.

En los libros del tercer ciclo, la estructuración es muy distinta. En el libro de quinto, solo aparecen mencionados los aspectos que se comentan en el tema 2, los sonidos $[x]$ y $[R]$, los cuales plantea como repaso (p. 26). El único aspecto reseñable lo encontramos en el número de ejercicios, que no en el tipo, siendo estos más numerosos (al incluir también el sonido [R]), y en la extensión del dictado, apareciendo ahora dos y siendo más extensos que en el ciclo anterior.

El libro de sexto solo menciona el uso de la j, en el tema 11, Uso de la J (p. 156). Comienza explicando la norma ortográfica, indicando que se escriben con $j$ :

- Las formas de los verbos que llevan el sonido $[x]$ y que no tienen ni $g$ ni $j$ en su infinitivo.

- Las palabras que terminan en -aje o -eje.

- Las palabras que empiezan por aje- o eje-. (Exceptuando las palabras agenda, agencia y agente).

Cabe reseñar que para cada una de las palabras anteriores aparecen unos ejemplos que acompañan a la norma, cosa que no ocurría en los manuales del segundo ciclo. Asimismo, continúa siendo mayor el número de ejercicios, pero conservando la misma estructura (completar oraciones, formar verbos a partir de sustantivos y sustantivos terminados en -aje a partir de verbos, escribir oraciones con grupos de palabras..., acabando con dos dictados). 
Revisión del manual de la editorial SM (Proyecto Timonel)

De este manual revisaremos los libros pertenecientes al tercer ciclo, además del libro de cuarto curso. Esta editorial, divide los contenidos de la lengua de forma muy parecida en los ciclos segundo y tercero. En el Proyecto Tirolina, libro de cuarto curso, la estructuración seguida es: comprender el texto, vocabulario-ortografía, gramática, escribir, hablar, literatura, repaso y, por último, competencias básicas. El Proyecto Timonel, en cambio, establece: comprensión lectora, vocabulario, ortografía, gramática, expresión escrita, expresión oral, literatura y, finalmente, competencias básicas. Podemos apreciar una separación, en este último ciclo, de los apartados vocabulario y ortografía, los cuales se compartían en el libro de cuarto curso, ofreciendo una cantidad mayor de ejercicios relacionados con la ortografía. Asimismo, cabe destacar, en el Proyecto Timonel, la inclusión de un cuadernillo de ortografía en el cual encontramos las reglas ortográficas relacionadas con la acentuación, los signos de puntuación y la escritura de ciertas letras, entre las que se incluyen las que son nuestro objeto de estudio; un vocabulario básico con el fin de fijar y almacenar ciertas palabras en la memoria semántica del lector por medio de la ruta visual o léxica; y la inclusión de dictados para trabajar el vocabulario.

Al igual que en la editorial Santillana, analizaremos el tratamiento que esta editorial hace de las letras y sonidos $[\mathrm{g}]$ y $[\mathrm{x}]$, presentes en el apartado vocabularioortografía en el Proyecto Tirolina y en el apartado de ortografía del Proyecto Timonel.

En el libro de cuarto, encontramos las palabras terminadas en -aje, en el tema 6 (p. 82) y los verbos terminados en -ger y en -gir, tema 14 (p. 196). En ambos casos, comienza la explicación con una lectura seguida de la definición de la norma y la realización de unos ejercicios de aplicación fundamentados en completar oraciones, formar palabras terminadas en -aje a partir de verbos, la escritura de oraciones a partir de dibujos y un dictado. Es reseñable el apartado, que se incluye dentro de la sección de ortografía, de fichero ortográfico, aunque quizá, para nosotros, no se realice de la mejor manera posible al no partir de los intereses de los alumnos. Las normas ortográficas de las grafías $g$ y $j$ que se tratan en este manual son las siguientes:

- Tema 6: se escriben con $j$ todas las palabras terminadas en -aje.

- Tema 14: se escriben con $g$ todos los verbos que terminan en -ger, -gir, excepto tejer y crujir.

En el caso del tema 6, resulta Ilamativo que en la norma no se incluyan las palabras terminadas en -eje.

El proyecto Timonel, recoge las palabras con g, en el tema 11 (p. 154), y las palabras con $j$, en el tema 12 (p. 168). La tipología de los ejercicios sigue siendo la misma (clasificación, completar oraciones, escribir palabras, relacionar, fichero ortográfico, dictado...), utilizada a través de un enfoque, principalmente, transmisivo, aunque ahora divide las normas y, para cada división, se plantean unos ejercicios de aplicación. Las normas ortográficas de las grafías $g$ y j que se trabajan en este manual son:

- Tema 11

- Se escriben con g los verbos que terminan en -ger y -gir, excepto tejer y crujir.

- Se escriben con $g$ las palabras que empiezan por geo-, gest- y gen-, excepto jengibre-.

- Se escriben con g las palabras que acaban en -gen. 
Acompaña cada norma con algún ejemplo y además aparece un apartado titulado "recuerda" que indica que si una palabra se escribe con $g$, todas las palabras de su misma familia se escriben también con $g$.

- Tema 12

- Se escriben con $j$ todas las palabras que acaban en -aje.

- Las palabras que acaban en -jero, -jera, -jería, excepto ligero.

- Se escriben con $j$ los verbos tejer y crujir.

- Las formas verbales con el sonido $j$ cuyo infinitivo no lleva ni $g$ ni $j$.

Del mismo modo, aparecen ejemplos para cada norma y en el apartado "recuer$\mathrm{da}^{\prime \prime}$ aparecen las normas ortográficas relativas al uso de la grafía $g$ tratadas en el tema anterior.

Por último, en el libro de sexto curso, aparecen de forma conjunta, en el tema 8 (p. 110), las palabras con $g$ y con $j$. Los ejercicios que plantea son muy similares a los realizados en el curso anterior, de un nivel muy básico, y se trabajan las mismas reglas ortográficas, con la inclusión de las siguientes:

- Se escriben con g las palabras que acaban en -gia, -gio, -gión y -gional, excepto lejía.

- Se escriben con $j$ los verbos que terminan en -jear.

\section{INTERVENCIÓN EN LAS AULAS}

Debido a la dificultad, cada vez más latente y que llega, incluso, a afectar a estudiantes de nivel universitario, para identificar la norma que rige, en cada caso, el correcto uso de las grafías $g$ y/o $j$, decidimos realizar un estudio de corte descriptivo en cuatro colegios de Cieza ${ }^{5}$, localidad perteneciente a la Región de Murcia, durante los meses de enero y febrero del año 2015.

Dicho estudio se realizó con el objetivo de intentar comprobar el dominio, tanto a nivel práctico como teórico, de la competencia ortográfica referida al uso de las grafías $g$ y $j$ que tienen los alumnos al final de la etapa formativa de Educación Primaria.

Para poder llevar a cabo el objetivo propuesto, contamos con cuatro centros participantes. De ellos, dos centros son de titularidad pública, mientras que los otros dos son concertados. El tipo de muestreo utilizado ha sido deliberado ya que, de acuerdo con Buendía, Colás y Hernández (2010, p. 30), este tipo de muestreo "consiste en seleccionar la muestra de forma deliberada porque los sujetos poseen las características necesarias para la investigación. Los resultados son difíciles de generalizar". Por lo que la muestra del estudio la ha constituido el alumnado de sexto curso de Educación Primaria, contando con un total de 120 alumnos, de los cuales 58 eran chicas y 62 chicos.

Como instrumento de recogida de información se utilizó un cuestionario, el cual se aplicó a la muestra del estudio. En él, los estudiantes debían responder a dos actividades para valorar el dominio de la competencia ortográfica en el uso de las grafías g y $j$. En la primera, de corte práctico, debían señalar únicamente, entre veinte pares de palabras, aquellas que estuvieran bien escritas (ver figura 1).

5. Para mantener el anonimato de los centros, estos se denominarán con las grafías A, B, C y D. 


De los siguientes pares de palabras, rodea con un círculo la palabra que consideres
que está bien escrita.
digimos dijimos escoje escoge lenguaje lenguage agente ajente
viaje viage pasage pasaje mejillón megillón crugir crujir
rujir rugir $\quad$ girafa jirafa
ageno ajeno tejido tegido pájina
agencia ajencia traduje traduge prestigio prestijio

Figura 1. Actividad práctica

En la segunda actividad, de corte teórico, los alumnos debían contestar anotando, en función de los conocimientos adquiridos durante la etapa educativa de Educación Primaria, aquellas normas ortográficas que regulan el uso de la grafía $j$ (ver figura 2).

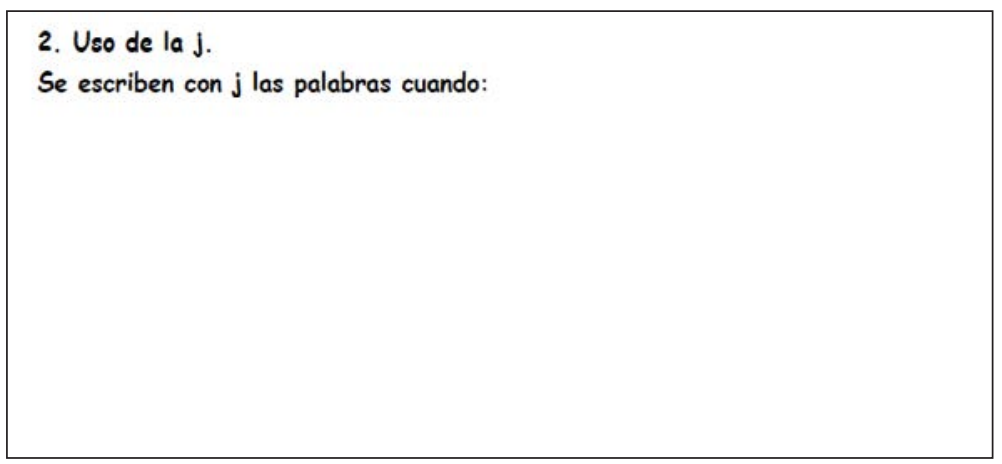

Figura 2. Actividad teórica

Además, en el cuestionario también se les preguntaba acerca de la frecuencia con la que leían por placer y con la que consultaban el diccionario en el caso de tener alguna duda ortográfica ante la escritura de cualquier palabra.

\section{ANÁLISIS DE LOS RESULTADOS Y DISCUSIÓN}

En lo que respecta a los resultados obtenidos, estos fueron, en general, peor de lo esperado. Así, en lo referido a la realización de la actividad de corte práctico, los resultados, por colegios, fueron los siguientes:

- En el colegio A (figura 3), de los treinta y nueve alumnos encuestados, solo tres realizaron la actividad correctamente. 
- En el colegio B (figura 4), ningún alumno, de los doce encuestados, realizó la actividad de manera correcta.

- En el colegio C (figura 5), de los cincuenta alumnos encuestados, solo uno la realizó sin cometer ningún error.

- En el colegio D (figura 6), solo tres alumnos, de los diecinueve encuestados, realizaron la actividad de forma satisfactoria.

\section{Colegio A}

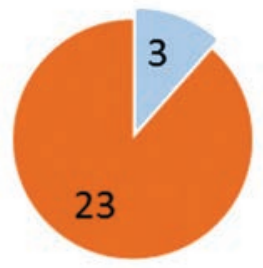

Figura 3. Resultados de la actividad práctica en el colegio $A$

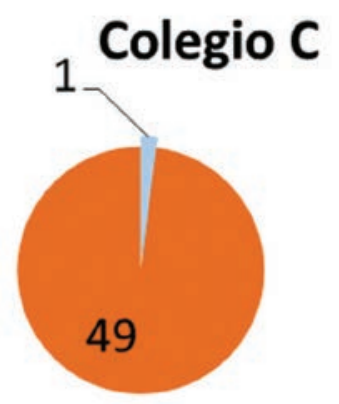

BIEN

- MAL

Figura 5. Resultados de la actividad práctica en el colegio $C$

\section{Colegio B}

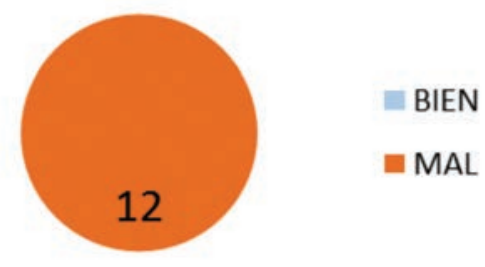

Figura 4. Resultados de la actividad práctica en el colegio $B$

\section{Colegio D}

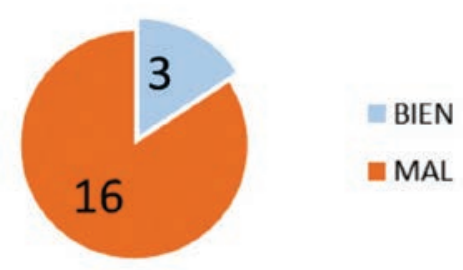

Figura 6. Resultados de la actividad práctica en el colegio $D$

Por lo tanto, podemos indicar, tal y como se recoge en la figura 7, aunando los datos de cada uno de los centros encuestados que, de los ciento veinte alumnos que componen el total de la muestra, solo siete alumnos han realizado la actividad de manera satisfactoria, siendo ciento trece el número de alumnos que la han completado con algunos errores.

En lo que respecta a los resultados de la actividad teórica destaca, principalmente, que existe un gran desconocimiento de las normas ortográficas por la gran mayoría de los estudiantes encuestados. 


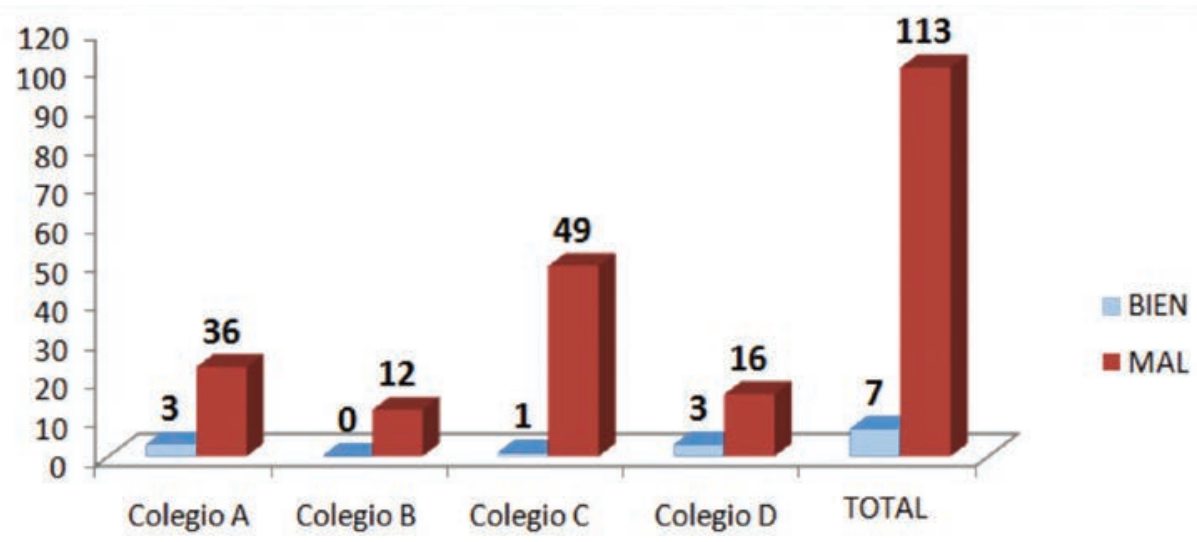

Figura 7. Resultados globales de la actividad práctica

Para el análisis y clasificación de las respuestas de los alumnos, las categorizamos en cinco bloques según el número de normas ortográficas mostradas en ellas. Así, nada se correspondía con ninguna norma acertada o dejar el ejercicio en blanco; poco, con alguna norma correcta; y así sucesivamente.

A continuación mostramos los resultados de esta actividad de corte teórico. Al igual que en la anterior, primero por colegios y, finalmente presentando, el total de la muestra.

- En el colegio A (figura 8), de los treinta y nueve alumnos encuestados, solo dos mostraron el conocimiento de alguna norma ortográfica.

- En el colegio B (figura 9), ningún alumno, de los doce encuestados, realizó la actividad de manera correcta. Nueve alumnos no contestaron.

- En el colegio C (figura 10), de los cincuenta alumnos encuestados, veintidós conocían alguna norma.

- En el colegio D (figura 11), ningún estudiante, de los diecinueve encuestados, conocía alguna norma ortográfica sobre la grafía $j$.

\section{Colegio A}

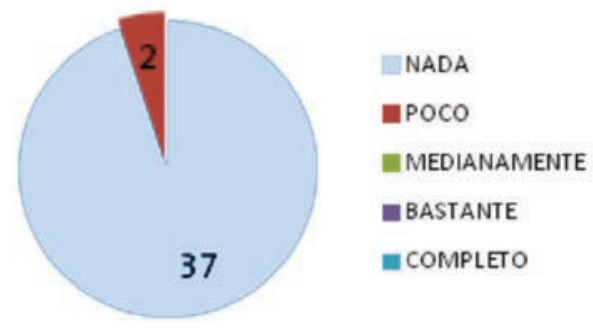

Figura 8. Resultados de la actividad teórica en el colegio A

\section{Colegio B}

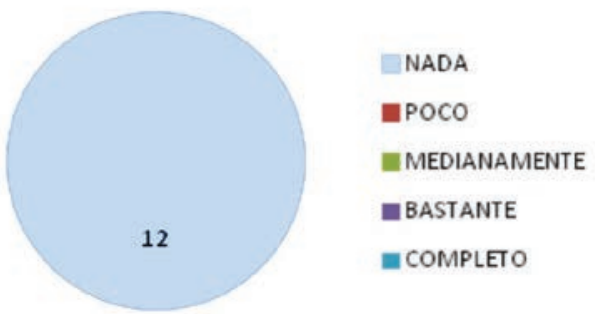

Figura 9. Resultados de la actividad teórica en el colegio $B$ 


\section{Colegio C}
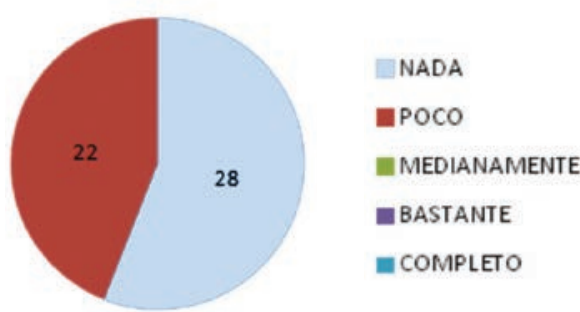

Figura 10. Resultados de la actividad teórica en el colegio $C$

\section{Colegio D}

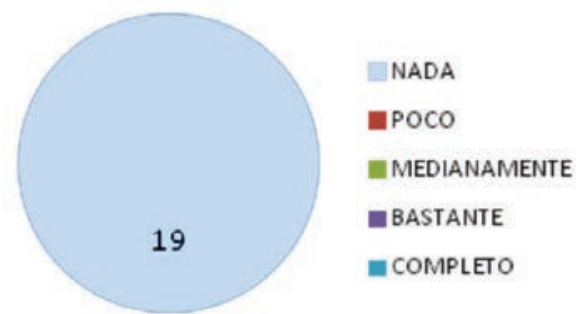

Figura 11. Resultados de la actividad teórica en el colegio D

En la figura 12 podemos apreciar el resultado global de las respuestas de los alumnos a esta actividad. En ella constatamos que, de los 120 alumnos, solo 24 presentaban un sucinto conocimiento de alguna norma ortográfica de la grafía $j$.

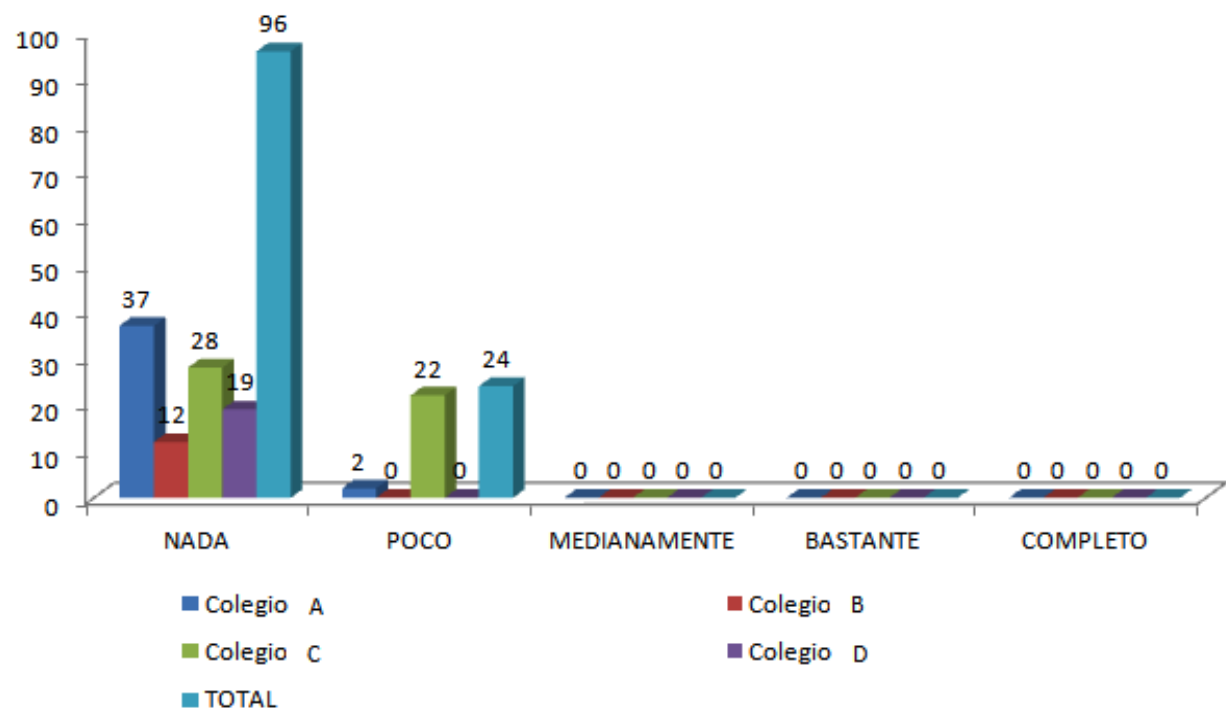

Figura 12. Resultados globales de la actividad teórica

En lo que respecta a la frecuencia de lectura y de consulta del diccionario, tal y como se aprecia en la tabla 1, la mayoría de los discentes lee poco u ocasionalmente y solo consultan el diccionario en determinadas ocasiones.

Para concluir, queremos destacar el gran número de estudiantes encuestados que desconocen las normas ortográficas, a pesar de que estas han formado parte de los contenidos planteados en los libros de texto. El desconocimiento de la teoría lleva 
a la realización errónea de aquellas actividades de carácter más práctico, ya sean similares a la planteada o en las que se requiere la elaboración de textos, en los que el conocimiento de las normas ortográficas se hace necesario.

Tabla 1. Frecuencia de lectura y consulta del diccionario

\begin{tabular}{ccccccccc}
\hline & \multicolumn{3}{c}{ Frecuencia de lectura } & & \multicolumn{3}{c}{ Consulta diccionario } \\
\hline & Nunca & Poco & Ocasionalmente & Bastante & Mucho & Nunca & A veces & Siempre \\
\hline Chico & 3 & 20 & 28 & 10 & 1 & 13 & 37 & 12 \\
Chica & 7 & 28 & 19 & 4 & 3 & 44 & 11 \\
\hline
\end{tabular}

\section{Propuestas de mejora}

Creemos necesario, sobre todo a la vista de los resultados obtenidos, que se produzca un cambio en la didáctica de la ortografía. Este reajuste, resulta todavía más apremiante en aquellos centros en los que se utiliza el libro de texto como único recurso de enseñanza en las clases de Lengua Castellana y Literatura.

Somos conscientes de que, de acuerdo con las nuevas teorías del aprendizaje, principalmente el constructivismo, hemos de superar el enfoque transmisivo tradicional, basado en la clase magistral y en el que los alumnos son meros receptores de conocimiento, y apostar por un enfoque de corte más comunicativo en el proceso de enseñanza-aprendizaje, haciendo que sean los estudiantes los principales protagonistas de este. Y es que, como indica Camps (1993, p. 36):

Aprender no significa recibir pasivamente unos conocimientos externos; por el contrario, es una actividad por la cual la persona que aprende interioriza unos conocimientos, unos conceptos, integrándolos en los sistemas que ha elaborado hasta ese momento y que, lógicamente, deberá reestructurar a partir de la nueva información.

Trabajar la ortografía desde un enfoque comunicativo permite dotar al proceso de enseñanza-aprendizaje de una gran significatividad, que difícilmente se podría conseguir desde un enfoque transmisivo. Máxime si, como Camps (1993, p. 43), partimos de la idea de que "el aprendizaje de la ortografía solo tiene sentido si se enmarca en un aprendizaje de la lengua escrita entendida como capacidad para la expresión y comunicación por escrito". Creemos que para los discentes puede resultar muy difícil comprender la necesidad de la ortografía si no sienten la necesidad de escribir.

Antes de pasar a proponer actividades prácticas para el trabajo de las normas ortográficas tratadas en este artículo ( $g$ y j ), queremos destacar la importancia que tienen los docentes en el proceso de enseñanza-aprendizaje. Por un lado, son quienes mejor conocen a sus alumnos y, de acuerdo con el constructivismo, deben servir de guía a los discentes para que progresen en la interiorización de conocimientos, siempre a partir del bagaje previo que estos posean. Por otro, son los docentes quienes deben propiciar situaciones reales de escritura que les permitan analizar los errores y faltas de los educandos para luego comentarlas en clase. De poco sirve hacer escribir a los 
alumnos para devolverles el escrito con un gran mosaico de correcciones en rojo que luego no van a ser comentadas. Bueno, puede servir para que se avergüencen de lo que hacen y comenzar a odiar o perder el gusto por la escritura.

\section{Actividades prácticas para trabajar las normas ortográficas tratadas ${ }^{6}$}

Antes de citar ninguna propuesta, creemos conveniente indicar que es aconsejable que los docentes realicen, al menos de vez en cuando, talleres de escritura en sus aulas. Es preciso situar al alumnado ante contextos de escritura. Eso sí, situaciones con un fin determinado. Además, es importante, que los escritos de los estudiantes rompan con la monotonía y salten la barrera del aula para que puedan ser disfrutados por toda la comunidad educativa. En definitiva, que los discentes se sientan escritores. A todos nos resulta altamente aburrido escribir para nada, nuestros alumnos no van a ser menos.

Algunas de las actividades prácticas que creemos pueden mejorar la enseñanza de la ortografía son las siguientes:

- Diccionario de clase. Realizar fichas con palabras, del libro de texto, de lectura, propuestas por el docente, etc., que tengan algún tipo de dificultad (ortográfica, de comprensión...). Debe contener la palabra, un dibujo, su definición y una frase en la que se utilice la palabra. Se puede organizar por temática o por orden alfabético.

Ejemplos de palabras: mejillón, lejía, traje (prenda de vestir), jersey, jirafa, agenda...

- Libreta de consulta ortográfica. Consiste en el registro de palabras que siguen una determinada norma ortográfica, y posterior clasificación de estas en fichas con la norma que cumplen.

Ejemplo:

Norma ortográfica: se escriben con $j$ las palabras terminadas en -aje y en -eje. Palabras: viaje, traje, espionaje, paisaje...

- El error creativo. Consiste en aprender de los errores, jugar con ellos. Se trata de inventar historias algo disparatadas con aquellas palabras que son susceptibles de ser escritas erróneamente.

Ejemplo: crugió.

"En el bosque, un monstruo horrible perseguía a un indefenso niño. Este, al ver que no podía seguir corriendo ya que estaba muy cansado, decidió esconderse. Vio una cueva y, rápidamente, se dirigió hacia allí. Justo antes de entrar a la cueva pisó una rama y esta crugió. Menos mal que, al estar escrita con g en vez de con j, esta no sonó y el monstruo no pudo oír al niño".

- Redacciones para trabajar las normas ortográficas de forma práctica. Dar a los alumnos diversas consignas para que escriban una redacción, cuento, historia, etc., relacionadas con las normas ortográficas de la $g / j$.

Ejemplo: escribe una historia que contenga cinco palabras que terminen en -aje y dos palabras que comiencen por age-.

6. Además de las normas tratadas pueden utilizarse para cualquier otra. 


\section{Conclusiones}

En base al estudio realizado, son varias las conclusiones que obtenemos. En primer lugar, apreciamos que los currículos educativos no recogen las normas ortográficas que deben adquirirse durante la etapa de la Educación Primaria, quedando estas al amparo de los libros de texto. Por ello, opinamos que, tal vez, los currículos deberían marcar más la línea a seguir en la enseñanza de la ortografía, como sí hacen con otros contenidos de Lengua Castellana y Literatura.

Utilizar el libro de texto como único recurso hace que el proceso de enseñanzaaprendizaje siga un enfoque, fundamentalmente, transmisivo, pues así lo atestigua el análisis de algunas de las editoriales más utilizadas en los diferentes colegios de la localidad de Cieza y estudios como los de Navarro (2015). Por ello, creemos que la enseñanza de la ortografía debe experimentar un cambio respecto a lo que se ha hecho hasta ahora, apostando por un enfoque más lúdico-creativo ya que, como indican López y Encabo (2012, p. 30), "consabido es que cuando el alumnado hace algo con agrado, lo hace de un modo correcto y no solo eso sino que, simultáneamente, progresa en la materia en la que se halla trabajando".

Como se ha apreciado en el estudio realizado, hay graves carencias en la adquisición de las distintas normas ortográficas. En nuestro caso, en el estudio de la adquisición del uso de las grafías g y j, podemos apreciar cómo la gran mayoría de los alumnos encuestados no domina la adquisición de estas normas, como queda plasmado en las actividades planteadas a los alumnos. Esto queda latente, no solo al no ponerlas en juego durante la elección, entre pares de palabras, de la palabra correcta, sino también al ser preguntados directamente por ellas. Todo ello a pesar de que, cómo se ha podido observar, los libros de texto recogían numerosas de las normas ortográficas de estas grafías y, por ende, las han estudiado desde, al menos, el cuarto curso de Educación Primaria.

\section{REFERENCIAS BIBLIOGRÁFICAS}

Avendaño, F. (2007). La enseñanza de la ortografía: un problema en tres dimensiones. Revista Escrita, 8, 1-8.

Buendía, L., Colás, P. y Hernández, F. (2010). Métodos de Investigación en Psicopedagogía. Madrid: McGraw-Hill.

Camps, A., Milian, M., Bigas, M., Camps, M. y Cabre, P. (1993). La enseñanza de la ortografía. Barcelona: Graó.

Cassany, D. (2003). Describir el escribir. Cómo se aprende a escribir. Barcelona: Paidós Comunicación.

Díaz, M. R. (2008). Preocupaciones docentes y enfoque didáctico en la enseñanza de la ortografía. Docencia e Investigación. 18(1), 49-78.

Díaz, M. R. y Manjón, A. (2010). Enseñanza y procesos de mejora en el aprendizaje ortográfico. Docencia e Investigación, 20(1), 87-124.

González, R. M. (2002). Poder escribir: programa de entrenamientos de los procesos cognitivos de la escritura. Manual del educador. Madrid: EOS. 
López, A. y Encabo, E. (2012). Estrategias didácticas para la enseñanza de la lengua y la literatura. Murcia: Diego Marín.

Decreto número 198/2014, de 5 de septiembre, por el que se establece el currículo de la Educación Primaria en la Comunidad Autónoma de la Región de Murcia. Boletín Oficial de la Región de Murcia, 6 de septiembre de 2014, núm. 206, pp. 33054-33556.

Decreto número 286/2007, de 7 de septiembre, por el que se establece el currículo de la Educación Primaria en la Comunidad Autónoma de la Región de Murcia. Boletín Oficial de la Región de Murcia, 12 de septiembre de 2007, núm. 211, pp. 26387-26450.

Navarro, A. F. R. (2015). Enseñanza de la ortografía, tratamiento didáctico y consideraciones de los docentes de Educación Primaria de la provincia de Almería. Investigaciones Sobre Lectura, (4), 7-24.

Real Academia Española (2010). Ortografía de la lengua española. Madrid: España.

Rodari, G. (1973). Gramática de la fantasía. Barcelona: Reforma de la escuela.

Sotomayor, C., Molina, D., Bedwell, P. y Hernández, C. (2013). Caracterización de problemas ortográficos recurrentes en alumnos de escuelas municipales chilenas de $3^{\circ}, 5^{\circ}$ y $7^{\circ}$ básico. Revista signos, 46(81), 105-131.

Zayas, F. (2007). Ortografía y aprendizaje de la lengua escrita. Textos de didáctica de la lengua y la literatura, 5, 103-113.

\section{Libros de texto}

Romo, L. (Ed.) (2008). Lengua castellana $3^{\circ}$ primaria. Proyecto: La casa del saber. Madrid: Santillana Educación.

Romo, L. (Ed.) (2008). Lengua castellana $4^{\circ}$ primaria. Proyecto: La casa del saber. Madrid: Santillana Educación.

Romo, L. (Ed.) (2009). Lengua castellana $5^{\circ}$ primaria. Proyecto: La casa del saber. Madrid: Santillana Educación.

Romo, L. (Ed.) (2009). Lengua castellana $6^{\circ}$ primaria. Proyecto: La casa del saber. Madrid: Santillana Educación.

Oro, B., Cantalejo, A., González, M. R., Gil, C., Alonso, S., Martí, M. y Hernández, O. (2009). Lengua 5 EP. Proyecto Timonel. Madrid: Ediciones SM.

Oro, B., Cantalejo, A., González, M. R., Gil, C., Alonso, S., Martí, M. y Hernández, O. (2009). Lengua 6 EP. Proyecto Timonel. Madrid: Ediciones SM.

Oro, B., González, M. R., Gil, C. y Martí, M. (2009). Lengua 4 EP. Proyecto Tirolina. Madrid: Ediciones SM. 